\title{
Menopausal Health Status of Nepalese Women
}

\author{
Swaraj Rajbhandari, ${ }^{1}$ Raj Kumar Subedi, ${ }^{1,2}$ Ganesh Dangal, ${ }^{1,3}$ Anjana Phuyal, ${ }^{4}$ Achala Vaidya, ${ }^{1}$ Aruna Karki, ${ }^{1,3}$ \\ Heera Tuladhar,' Bandana Sharma Gurung, 'Lalita Joshi, 'Sushila Shrestha' \\ 'Menopause Society of Nepal (MESON), Kathmandu, Nepal, ${ }^{2}$ Central Institute of Science and Technology (CIST), Nepal, \\ ${ }^{3}$ Kathmandu Model Hospital, Kathmandu, Nepal, ${ }^{4}$ VA Boston Healthcare System, MA, USA.
}

\section{ABSTRACT}

Introduction: Menopause is an unavoidable and sometimes problematic condition in which women may suffer from a number of health problems. Knowledge of the major symptoms associated with menopause helps reduce the burden and stress associated with the condition. In this context, a study was conducted to establish baseline data regarding menopausal health problems among Nepalese women.

Methods: A descriptive cross-sectional study was conducted among 2000 women aged over 40 years to identify their knowledge, attitude and practice related to menopausal health problems. Data was collected by interviewing the women and doing physical examination. Analysis was done using descriptive statistics and SPSS software was used for data analysis.

Results: A cohort of 2073 women (ages 40-60 years) participated in the research, among them 2000 yielded complete response. The study revealed that 820 (41\%) women had reached menopause. The average age of menopause was 48.7 years. Majority of the women 1183 (59.2\%) in the study did not know about menopausal health problems. Abnormal bleeding 353 (17.65\%), sweating 315 (15.75\%), hot flushes 299 (14.95\%), joint/muscle pain 285 (14.25\%) were the most common menopausal symptoms known by the women. Joint pain 736 (36.8\%), hot flushes 584 (29.2\%), irregular bleeding $582(29.1 \%)$ were the most common experienced symptoms of menopause and only $586(29.3 \%)$ consulted the health workers to alleviate menopausal symptoms. Moreover, most of the women 926 $(46.3 \%)$ accepted menopause as a part of life.

Conclusions: The research has tried to establish the baseline of menopausal health problems in the Nepalese women. The average age of menopause was 48.7 years. Majority did not know about menopausal health problems. Further researches with nationally representative sample are recommended to further explore the menopausal health problems of Nepalese women.

Keywords: health problems; menopause; Nepal; women.

\section{INTRODUCTION}

Menopause, a universal experience, is the permanent cessation of menstruation when the menstrual cycle stops for longer than 12 months. ${ }^{1,2}$ Menopause is a state that allows for the subsequent disease in women with other risk factors. ${ }^{3}$ The perimenopausal years are associated with weight gain, increased central adiposity and decreased physical activity. ${ }^{4}$ Menopause is related to chronic diseases, most notably reproductive cancers, osteoporosis, and heart disease ${ }^{5}$ It is associated with

Correspondence: Dr. Swaraj Rajbhandari, Menopause Society of Nepal (MESON), Kathmandu, Nepal. Email: swarajp $11 @$ gmail.com, Phone: +977-9851099600. 
decreased whole body fat oxidation during exercise. ${ }^{6}$ To date, knowledge of menopause is based on a small proportion of predominantly ill women. ${ }^{7}$ Clinical features include incontinence, sexual dysfunction, increased fracture, and cardiovascular disease. ${ }^{8}$ Promoting positive attitudes to menopause, healthy lifestyles and stress reduction can be used as part of menopausal care. $^{9}$

Women with a negative attitude towards menopause were more likely to report symptoms compared to women with a positive attitude towards menopause. ${ }^{10}$ This study aimed to measure the knowledge, attitude and behavior related to menopause among Nepalese women.

\section{METHODS}

A descriptive cross-sectional study was conducted among 2000 women aged more than 40 years to identify knowledge, attitude and practice related to menopausal health problems. This pilot study was conducted in three different districts of Nepal viz. Kathmandu, Lalitpur and Bhaktapur from July 2014 to February 2015.

Ethical approval was granted through IRC of Public Health Concern Trust Nepal (phect-NEPAL) as the study was conducted in its hospitals/clinics and its catchment areas. Monitoring and evaluation of the study was done by the core research team and MESON executives.

Following the clinical exam with their doctor, women were invited to participate in the interviews. A research assistant discussed the study outline and asked for their consent to participate. The information letter was read to women who were illiterate and they provided a thumbprint with the signature of an independent witness to provide informed consent. Initially, the participants completed a demographic questionnaire with assistance from the research assistant. There were questions regarding their age, educational status, literacy, occupation and birthing history. The semistructured interviews also involved questions regarding the participants' knowledge of menopause and its impacts. Pretesting was done in Kathmandu Model Hospital for the reliability test of tools and necessary adjustments were done. Content and face validity was maintained by experts' advice.

The study districts were selected purposively and sample was taken purposively from the clinics and health camps. A total of 2073 women were approached of which 73 forms being incomplete were not included in the analysis. This yielded a sample size of 2000 . A questionnaire asked about the women's menstrual history, obstetric history, contraceptive history, life style, knowledge on menopausal symptoms, attitude towards menopause and menopausal problems experienced by the women. Their health seeking behaviour during menopause was also assessed. A group of experienced gynaecologists and researchers associated with Menopause Society of Nepal (MESON) were involved in conducting the study and MESON has plans to conduct a bigger and widely representative research based on this pilot study.

Data was entered in MS-EXCEL version 2013 and was analyzed by using IBM-SPSS version 20. Before data entry, a validated entry format was prepared on the basis of research tools in MS-EXCEL and trained data entry personnel were used for data entry. The research investigators ensured that all the data entered were complete and consistent. For data analysis, a trained and competent data analyst was employed who had prior experience in analysis of health related data. Data was analyzed using descriptive statistics. Measures of central tendency were computed for quantitative data. Categorical data were expressed using appropriate tables and charts.

\section{RESULTS}

Two thousands women were recruited for this study with a median age of 45 years (range 40-60 years) and variety of birthing histories, education and work backgrounds.

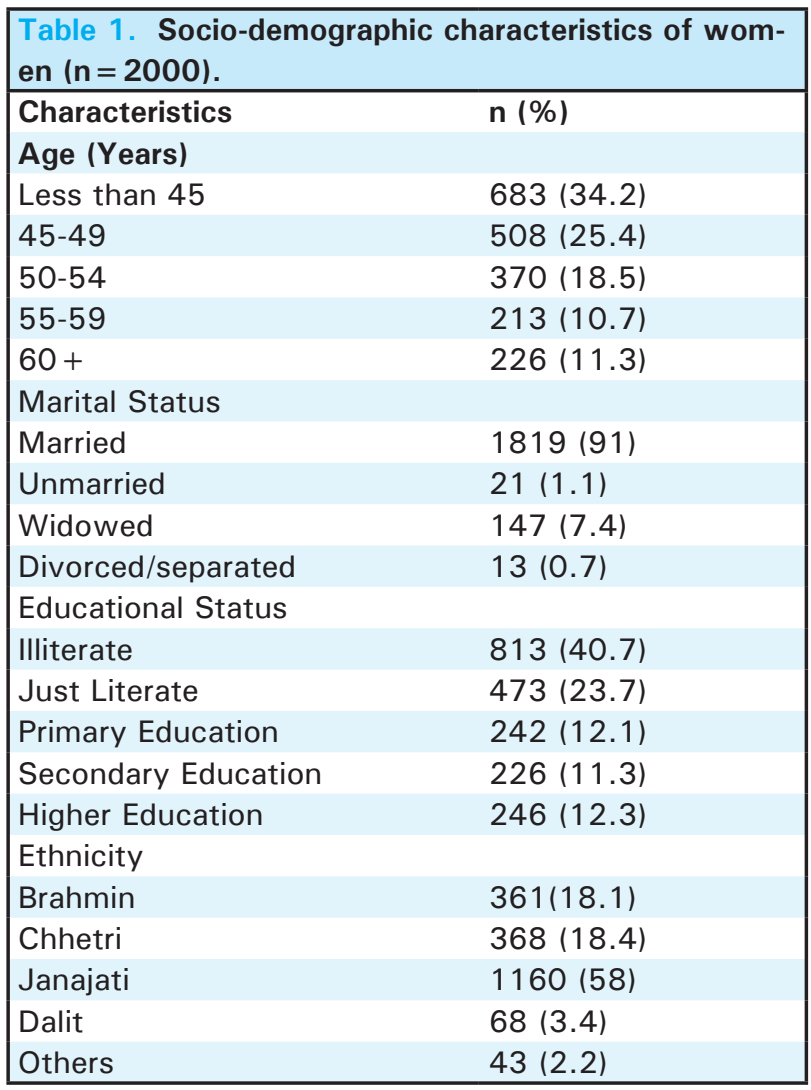


The majority of the women included in the study were aged $40-45(34.2 \%)$ years followed by women of $45-$ $49(25.4 \%)$ years and others. $226(11.3 \%)$ women were more than 60 years of age. A total of 1819 (91\%) women were married, $21(1.1 \%)$ women never married and $147(7.4 \%)$ women were widowed. More than $40 \%$ of the women were illiterate. The caste composition of the study participants was as follows; 1160 (58\%) Janajatis, 368 (18.4\%) Chhetris, 361 (18.1\%) Brahmins and 68 (3.4\%) Dalits (Table 1 ).

Similarly, the mean BMI of the participants was 25.97 years. Around $30 \%$ of the women had BMI in the range 18-24 (Figure 1).
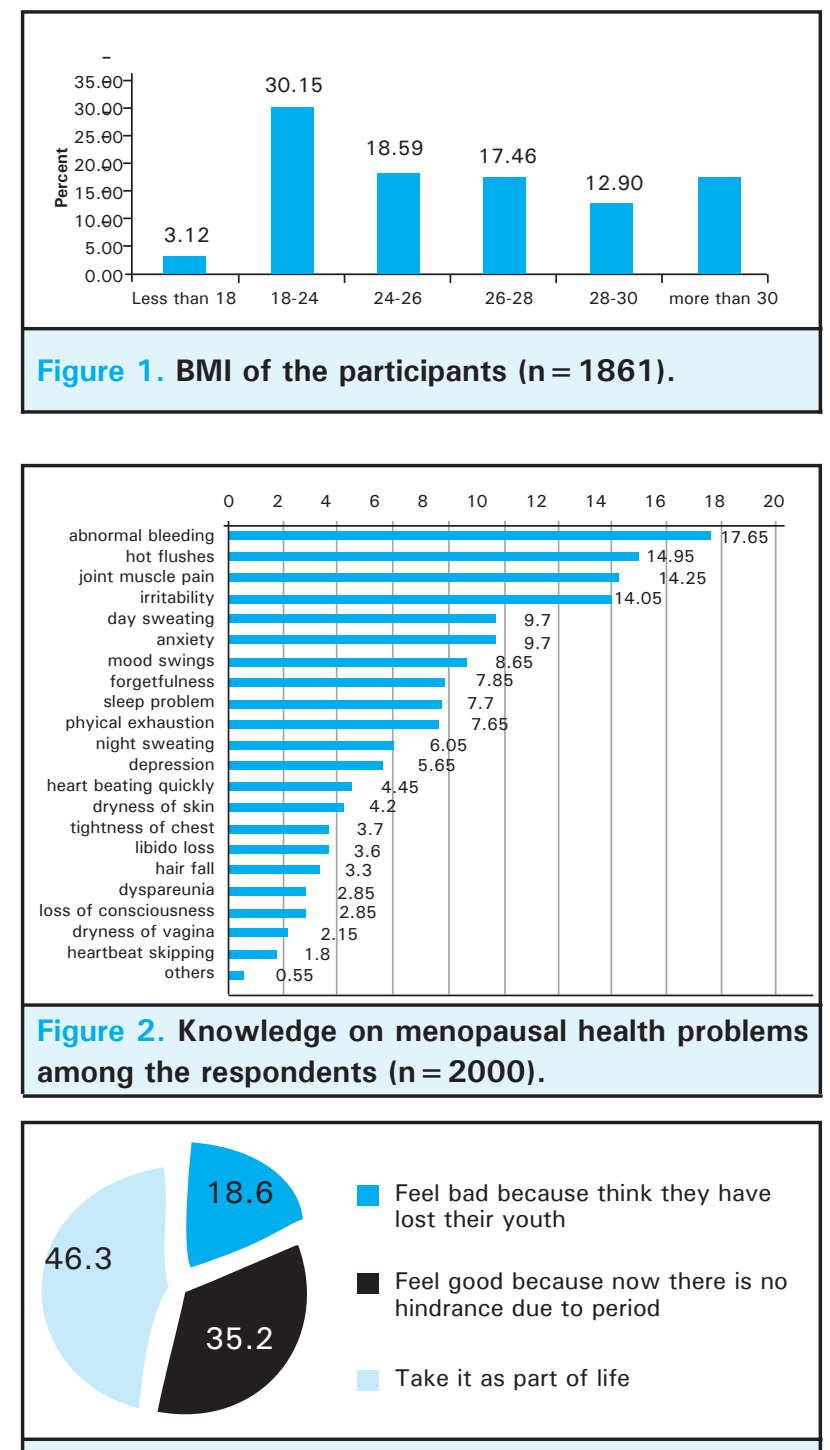

Figure 3. Attitude towards menopause $(n=2000)$.

The women had little knowledge on the menopausal symptoms. Only $41 \%$ knew about the menopausal health problems. Abnormal bleeding (17.65\%), sweating $(15.75 \%)$, hot flushes $(14.95 \%)$, joint/muscle pain $(14.25 \%)$ were the most common menopausal symptoms known by the women followed by other symptoms (Figure 2).

Similarly, while measuring attitu regarded menopause as a part of life (Figure 3).

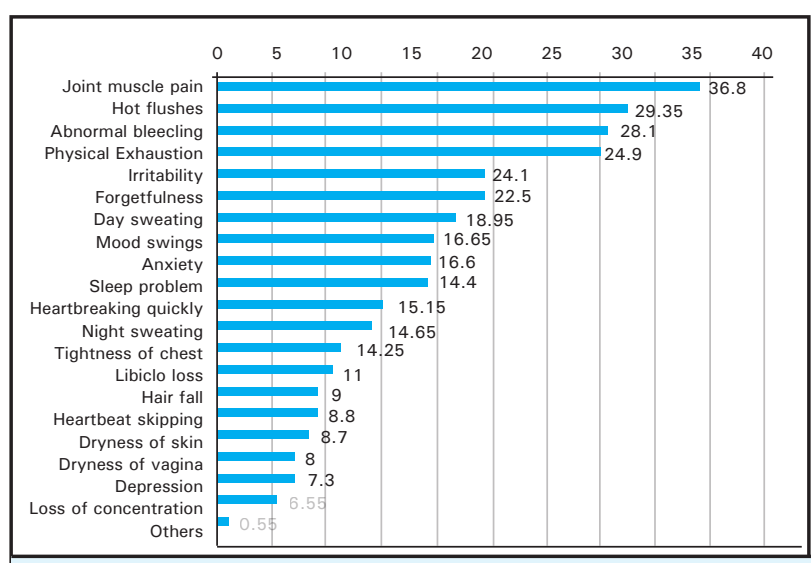

Figure 4. Menopausal health problems faced by the women.

Joint pain $(36.8 \%)$, hot flushes $(29.2 \%)$, irregular bleeding $(29.1 \%)$ were the most common experienced symptoms of menopause (Figure 4).

\section{DISCUSSION}

The women in this study were not familiar with many major menopausal problems but most had heard of a menopause. Low knowledge of menopausal features and problems is common for women globally regardless of educational status, ethnicity and parity.

The mean age of menopause according to the study was found to be 48.35 years with range from 31-52 years. A study done in four districts in Nepal (Kathmandu, Kaski, Makwanpur and Chitwan) have shown a mean age of menopause of 47 years, ${ }^{11}$ whereas the study done in Rupandehi District found the mean age to be 46.81 years. $^{12}$ A study done within Kathmandu Valley at Nepal Medical College found the mean age of menopause to be 49.9 years with range of 41.5 and 58.3 years. ${ }^{13}$ A study done by Chuni et al $^{14}$ in Kaski District found exact same menopausal age of 49.9 years. A study conducted among women living in high altitude in Mustang District also found the mean age of menopause to be 46.8 years. Therefore, based on these above studies we can state that the mean age of menopause varies between 46-50 years. This range of age of menopause is also in line with studies from other countries in south Asia, such as India and Pakistan that shows range between $46-49$ years. ${ }^{15}$ 
A meta-analysis including 36 studies across the Middle East, Asia, Latin America, USA, Europe, Australia and Africa, gave a mean age of menopause of 48.78 (95\% $\mathrm{Cl}$ : 48.33, 49.22). However, there was substantial heterogeneity between studies, with mean age ranging from 46 to 52 years. Sub-group analysis by geographical region demonstrated that ANM was generally lower among African (48 years), Latin American 147.2 years), Asian (48.7 years) and Middle Eastern countries (47.3 years), and was highest in Europe ( 50.5 years) and Australia (51.2 years), followed by the USA (49 years). ${ }^{16}$ This can indicate that mean age of reaching of menopause is higher in developed countries compared to developing countries. The mean age seems to vary not only among different countries but also within the same community. The study by Rajbhandari and colleagues has shown that ethnicity seemed to affect the age of menopause. They found that the age of menopause was higher among the Gurung community at 50 years than in the Brahmin/Chettri with the lowest age at 44 years. Various factors seem to affect the age at menopause. Other factors that may affect the age of onset of menopause are geographical variations, lifestyle, nutrition and socioeconomic status. ${ }^{16}$ In this study about $58 \%$ of women belonged to the Janjatis or ethnic groups and only about $12 \%$ of the patients had primary level and above education.

The usual belief is that Asian women experience less menopausal symptoms than Western women. ${ }^{17}$ This may be due to lack of knowledge, lack of education and conservative ideology. In this study about one in three $(36.8 \%)$ had experienced joint/muscle pain, followed by hot flushes $(29.25 \%)$, abnormal bleeding $(29.1 \%)$, physical exhaustion (28.1\%), irritability (24.9\%) and forgetfulness $(24.1 \%)$. These were the main symptoms found among the patients although other symptoms occurred with less frequency. This may be due to the fact that a large number of cases were studied in hospitals and clinics where the clients usually come with some sort of problem. Therefore this cannot be extrapolated to the general population. This is interesting because most of the patients were illiterate and belonged to minority ethnic groups and we would expect them to experience fewer symptoms in view of their cultural background and lack of knowledge. But despite the many symptoms only about $17 \%$ took some form of treatment for it as a menopausal symptom. This was also seen in the study done in Rupandehi where despite a large number of symptoms experience only $11 \%$ cases took modern treatment. ${ }^{12}$ Even in the study done by Marahatta, ${ }^{13}$ the most common symptom was joint pain and urinary symptoms and vasomotor symptoms constituted for $39 \%$ of cases. In western countries vasomotor symptoms and sleep disturbances, dry vagina account for the main menopausal symptoms. ${ }^{18}$ Most of the clients though experiencing these symptoms could not relate it to menopause. This was due to the lack of knowledge of menopause and symptoms. ${ }^{19}$ It was seen that $17 \%$ cases knew about abnormal bleeding and $14 \%$ about hot flushes, joint pain and irritability.

Most of the women took it as a part of life cycle and did not take it as a disease, which needs some treatment. This would therefore explain the various symptoms felt but very few seeking treatment for their complaints. Many (35\%) were relieved that there would be no more menses. This is typical of the Asian culture and reflects their socio-cultural and religious beliefs. The more educated the women are, the more likely they are to know about the various symptoms and treatment options available and therefore seek treatment for relief. Most of the studies that have been done in Nepal show that the literacy rate is very poor and therefore this affects their attitude too. Menopause is taken as a way of life and unless the symptoms become evident like abnormal bleeding or joint pain that affects mobility, most would loathe seeking treatment.

A limitation to this study was that all the participants were attending the women's health clinic at the hospital and may have increased knowledge and awareness of menopause after consulting with their doctor. One of the strengths of this study was the diversity in the sample population. Not all women had a menopause and the participants had a variety of birthing histories and backgrounds. Even though there was a small sample size recruited purposively, new information was captured from within the sample population.

\section{CONCLUSIONS}

The average age of menopause was 48.7 years. Majority of the women in the study did not know about menopausal health problems. The women had little knowledge on the menopausal symptoms; and abnormal bleeding, sweating, hot flushes, joint/muscle pain were the most common menopausal symptoms. The study showed that only about one third of the women sought medical help. Researchers, policy makers, academicians, civil society and other concerned authorities can use this study as the baseline data for further steps ahead. However, more researches need to be done in this area with nationally representative samples.

\section{ACKNOWLEDGEMENTS}

The authors and MESON sincerely thank all the contributors of the study and we would like to thank WHO Country Office Nepal for financially supporting MESON in carrying out the study.

\section{Conflict of Interest: None.}




\section{REFERENCES}

1. Lock M. Menopause in cultural context. Exp Gerontol. 1994;29(3-4):307-17. [PubMed]

2. 2. WHO. Research on the menopause in the 1990's. A report of the WHO Scientific Group. Geneva, Switzerland: World Health Organization; 1996. [PubMed]

3. Sowers MR, La Pietra MT. Menopause: its epidemiology and potential association with chronic diseases. Epidemiol Rev. 1995;17(2):287-302. [PubMed]

4. Simkin-Silverman LR, Wing RR, Boraz MA, Meilahn EN, Kuller LH. Maintenance of cardiovascular risk factor changes among middle-aged women in a lifestyle intervention trial. Womens Health. 1998;4(3):255-71. [PubMed]

5. Barrett-Connor, E. Epidemiology and the menopause: A global overview. International Journal of Fertility and Menopausal Studies. 1992;38:6-14. [PubMed]

6. Abildgaard J, Pedersen AT, Green CJ, Harder-Lauridsen NM, Solomon TP, Thomsen C, et al. Menopause is associated with decreased whole body fat oxidation during exercise. Am J Physiol Endocrinol Metab. 2013;304(11):E1227-36. [PubMed]

7. McKinlay JB, McKinlay SM, Brambilla DJ. Health status and utilization behavior associated with menopause. Am J Epidemiol. 1987;125(1):110-21. [PubMed]

8. Greendale GA, Judd HL. The menopause: health implications and clinical management. J Am Geriatr Soc. 1993;41(4):426-36. [PubMed]

9. Dennerstein L, Dudley E, Burger H. Well-being and the menopausal transition. J Psychosom Obstet Gynaecol. 1997;18(2):95-101. [PubMed]

10. Yanikkerem E, Koltan SO, Tamay AG, Dikayak Ş. Relationship between women's attitude towards menopause and quality of life. Climacteric. 2012;15(6):552-62. [PubMed]

11. Rajbhandari S, Amatya A, Giri K. Relation of Ethnicity and Menopausal Symptoms in Nepal. J South Asian Feder Menopause Soc. 2013;1(2). [Full Text]
12. Acharya D, Gautam S, Neupane N, Kaphle HP, Singh JK. Health Problems of Women above Forty Years of Age in Rupandehi District of Nepal. Int J Health Sci Res. 2013;3(3):29-36. [Link]

13. Marahatta RK. Study of menopausal symptoms among peri and postmenopausal women attending NMCTH. Nepal Med Coll J. 2012;14(3):251-5. [PubMed]

14. Chuni N, Sreeramareddy CT. Frequency of symptoms, determinants of severe symptoms, validity of and cut-off score for Menopause Rating Scale (MRS) as a screening tool: a cross-sectional survey among midlife Nepalese women. BMC Womens Health. 2011;11:30. [PubMed]

15. Nisar N, Sohoo NA. Severity of Menopausal symptoms and the quality of life at different status of Menopause: a community based survey from rural Sindh, Pakistan.118-30. [Full Text]

16. Schoenaker DA, Jackson CA, Rowlands JV, Mishra GD. Socioeconomic position, lifestyle factors and age at natural menopause: a systematic review and meta-analyses of studies across six continents. Int J Epidemiol. 2014;43(5):1542-62. [PubMed]

17. Loh FH, Khin LW, Saw SM, Lee JJ, Gu K. The age of menopause and the menopause transition in a multiracial population: a nation-wide Singapore study. Maturitas. 2005;52(3-4):169-80. [PubMed]

18. Woods NF, Mitchell ES. Symptoms during the perimenopause: prevalence, severity, trajectory, and significance in women's lives. Am J Med. 2005;118 Suppl 12B:14-24. [PubMed]

19. Ghimire N, Dhakal P, Norrish D, Dangal G, Sharma D, Dhimal M, et al. Menopausal Health Status of Women of Kapilvastu District of Nepal. J Nepal Health Res Counc. 2015;13(31):182-7. 